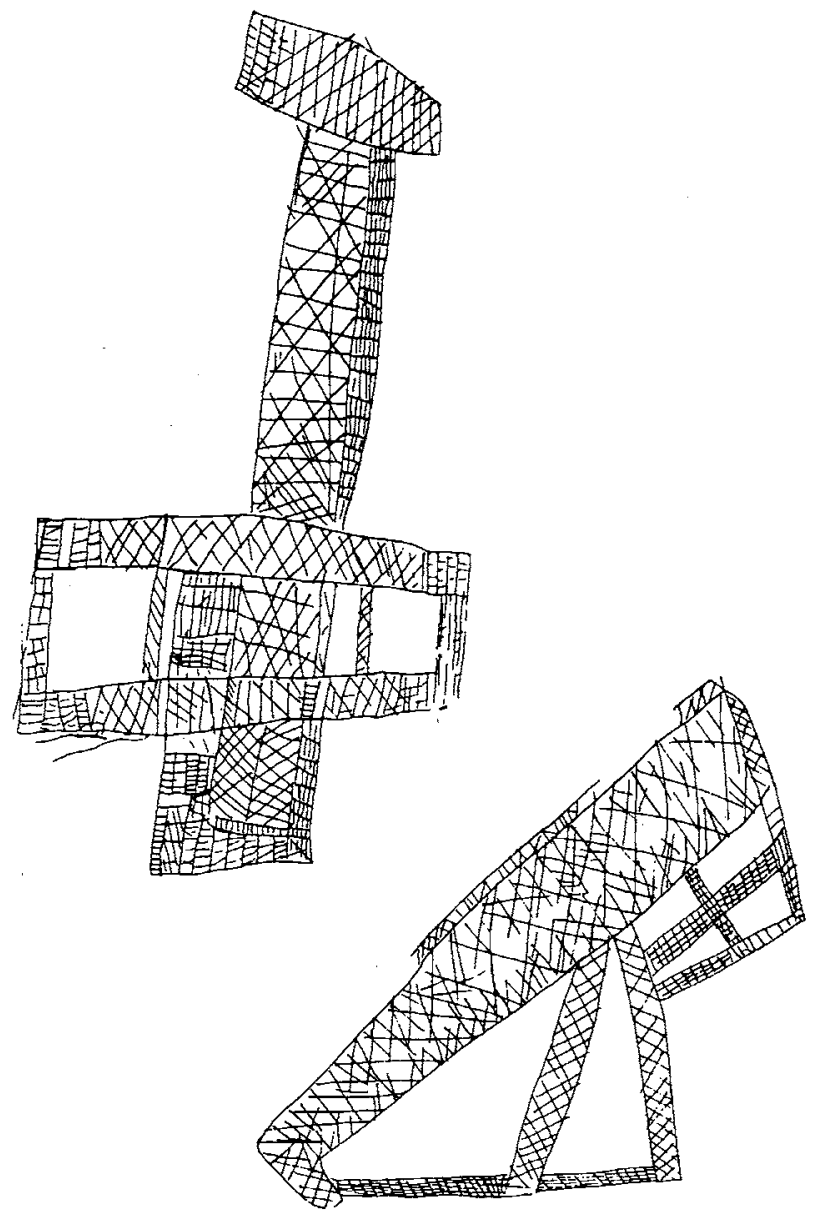

Plate 1: Engraving of aircraft on Warlpiri pearlshell pendant, redrawn to actual size. 


\section{R.E. Barwick}

My cover illustrations for volumes 1 to 5 of Aboriginal History have used motifs from Aboriginal rock art, redrawn for reproduction by offset printing. In response to Dr James Urry's request for Aboriginal renderings of aircraft, Mr R.G. Kimber of Alice Springs sent a photograph of a Warlpiri pearl-shell pendant in his possession. Warlpiri and Anmatjera Aborigines agreed that publication of this particular engraving was acceptable. The cover drawing for Volume 6 is derived from the engraving, redrawn to actual size.

When examining published studies of rock art I have been impressed by the numerous anatomical details incorporated in paintings and engravings of animal species. These details reveal the artist's acute observation of essential characteristics and in many instances enable a zoologist to make positive identification of the animal. I was struck by the possibility that this Warlpiri engraving might provide clues to a 'species'-level identification of the aircraft.

As is often the case in Aboriginal drawings of animals, the perspective of this engraving of an aircraft includes features that could be seen in both plan (in this case the underside as seen from the ground) and lateral views. A number of features are immediately obvious. The wings are squareended and the tail is elliptical in plan form with strong rib-like crosshatching. The slab-sided fuselage is slightly tapered and extends through the wing to an asymmetrical nose which is extended upwards as a separatelyhatched area. On the lower edge of the tail a distinct finely hatched band represents an oblique view of the flat underside of the tail. The engraving offers no definitive evidence for the aircraft being either a monoplane or biplane, but the 'wing' is bordered by a hatched frame with two prominent symmetrically placed transverse bars and it is possible that the fore and aft borders of this 'wing' represent upper and lower wings and the transverse bars indicate struts connecting two wings. Above the fuselage as it passes through the wing a second finely hatched rectangle is placed close to the upper transverse bar, seemingly either a continuation of the upper fuselage hump or perhaps the usually distinct petrol tank which was located in the mid-central segment of the upper wing in early aircraft. Such a tank is seen in Tiger Moths still flying today. Similarly, the upper rectangular extension of the nose probably indicates the bank of enclosed engine cylinders typical of certain aircraft with in-line engines mounted in a 'normal' upright position. This was a characteristic of the Gypsy Moth and Cirrus Moth but later aircraft such as the Tiger Moth have a similar engine in the inverted position so that the upper extension of the engine is lost and the propeller moves higher on the nose. 


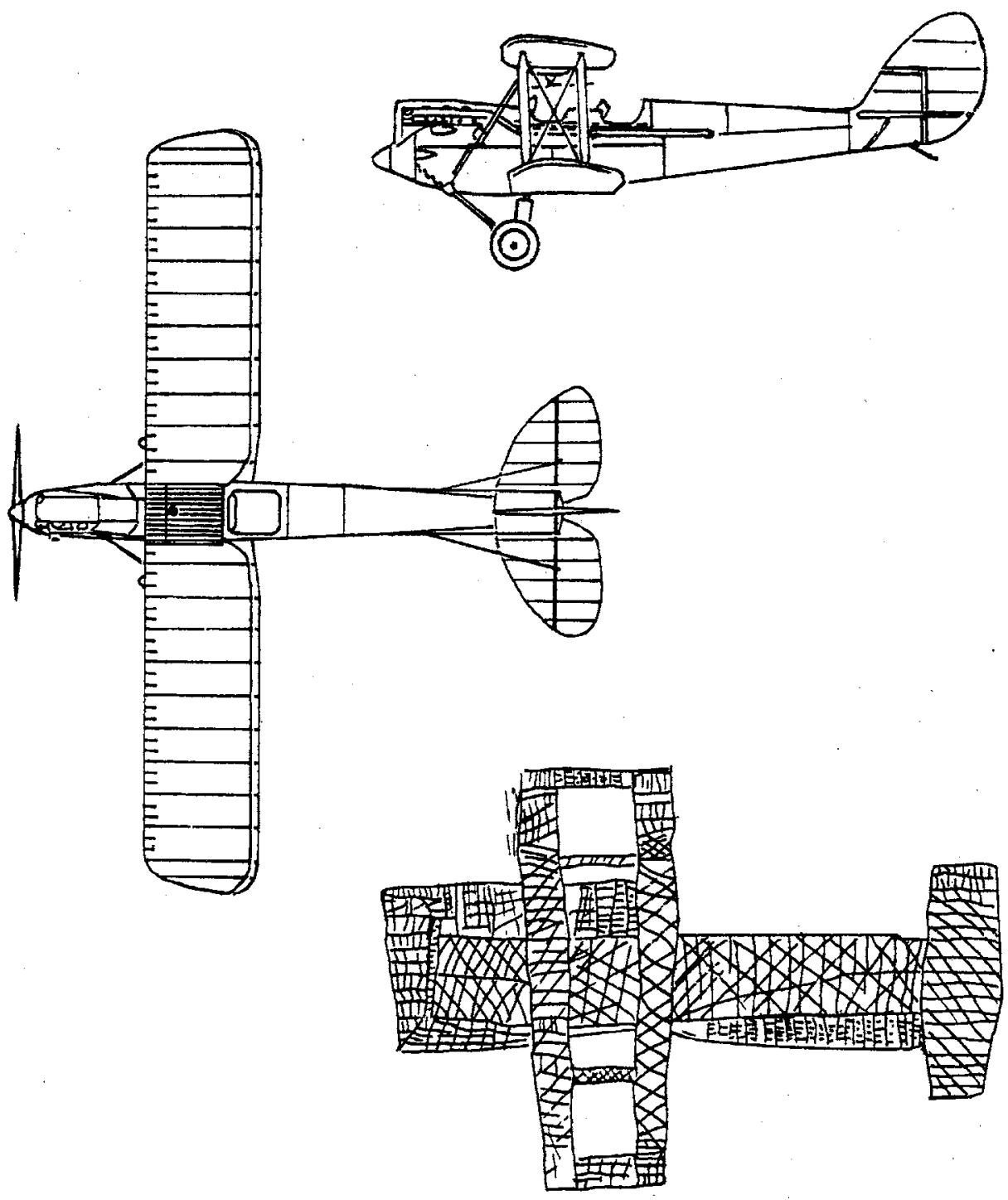

PLATE 2 
Before seeking information from Mr Kimber about the provenance of the engraved pendant I searched technical magazines on aircraft construction (which contain accurate scale drawings) for depictions of an aircraft which combined features apparent in the engraving: a raised nose, wing petrol tank, square-tipped wings and rounded tail. The plan and side views of a Gypsy-engined D.H. 60 'Gypsy Moth' (as shown in Plate 2) exemplified all four characteristics.

Another portion of this engraving seems to depict a crashed aircraft (see Plate 1). The tapered fuselage (showing a distinct tail fin) is cocked at an angle. A square-sided fuselage is again shown in oblique view. One framebordered 'wing' lying parallel to the fuselage carries a coss-hatched transverse bar within the frame. A second 'wing' extends from the fuselage at an acute angle. Both wings are tapered rather than parallel-sided, perhaps indicating damaged structures. A finely hatched narrow bar extends to the rounded tail fin. The attitude of this aircraft is typical of a forced landing: tipped over with nose buried and wings shattered so that the craft comes to rest with fuselage inverted.

Despite the inherent uncertainties of identification it seemed possible that this engraving depicted aircraft of the period when aeroplanes first flew in the Alice Springs area. I therefore searched the early records of Central Australian aviation for evidence that might confirm the anatomical clues which suggested a 'species' identification for this aeroplane. Crashes happened with some frequency in the early days when emergency landings on rough airstrips were not uncommon. For example, the first aircraft used by the Central Australian Gold Exploring Expedition, a Gypsy Moth D.H. 60 ('Golden Quest', VH-UNR) made just such a landing at Yayayi Creek, west of Papunya, in 1931.

Blakeley's posthumously-published account of this expedition describes the scene when he reached the site of Errol Coote's crash landing:

When the truck got down about two hundred yards we saw the plane.

What a relief? It was however standing on its nose and upside down and forty or fifty yards off the runway, tipped up on the bank of the big creek and lying on top of a big old rabbit warren that was all big holes where the natives had been digging them out. Both wings were crumpled up. ${ }^{1}$ Blakeley's description closely matches the pendant engraving. This aircraft was later removed to Alice Springs to be replaced by a similar aeroplane ('Golden Quest II', VH-UGX) in which the original Cirrus engine was replaced by the more powerful Gypsy engine recovered from the wrecked Golden Quest I. Errol Coote's book Hell's airport includes a photograph of the wrecked Golden Quest I at Aiai Creek after it had been pulled back on to its nose and wheels for eventual removal to Alice Springs. Another

$1 \quad$ Blakeley 1972:69. 
photograph shows Golden Quest II and a third Gypsy Moth ("Magic Carpet', VH-UJN) belonging to Bailey's Arnheim Company which was also flying in the Alice Springs area about the same time. ${ }^{2}$

Of course there can be no certainty that the aeroplane depicted in this engraving is a Gypsy Moth. Other well-known chartered aircraft were used by early aviators in the Centre: the Mackay Aerial Survey Expeditions ${ }^{3}$ of 1930-37 operated a Percival Gull, a D.H. Moth, a Monospar, a twinengined D.H. Dragon Fly, and D.H. Puss Moths as relief planes in 1935 and 1937. This shell pendant engraving is not, however, likely to be a representation of the forced landing of 'Kookaburra' (a Westland Widgeon II) since this monoplane successfully came to rest on its wheels and was not damaged in the emergency landing. ${ }^{4}$ The R.A.A.F. search party led by Flight-Lieutenant Charles Eaton which located 'Kookaburra' in 1929 employed five biplanes (three of which were lost in various mishaps), but all were of the D.H.9A type. ${ }^{5}$ These two-seat day bombers had a blunt square radiator in the nose and lacked the raised cylinders, typical of the Cirrus Moth and Gypsy Moth, which seem to be depicted as a raised rectangular extension of the nose in this engraving.

Two more engraved pearlshell pendants depicting aircraft are located in the ethnographic collection at the Institute of Anatomy in Canberra. ${ }^{6}$ One example (belonging to a set of eleven 'charms' from the northwest of Western Australia) clearly shows a biplane in plan view. The fuselage is complete with cockpit and tapered propeller. Two wings, shown in plan view as crossing the upper side of the fuselage, are joined by diagonally arranged struts. ${ }^{7}$ This detail supports my interpretation that the bars connecting the leading and trailing edge of the 'wing' on the aircraft used for the cover illustration are a rendering of the struts which connect upper and lower wings. As in the illustrated example, crosshatching on the wings of this second engraving may indicate a ground-based observer's view of the supporting ribs visible through the translucent fabric covering when the craft is in flight. A much simpler engraving appears on a shell pubic pendant from the Karadjeri of northern Western Australia. In this example, collected by A.P. Elkin in 1927-28, there is no crosshatching but each half of the square-ended wing bears three diagonal striations. The propeller is shown but the parallel-sided fuselage terminates in a jagged

Coote 1934: Plates IX, LIV

Clune 1942, Kimber 1982.

Nash 1982, Davis 1980.

Pentland 1978 .

I am indebted to Isabel McBryde and David Kaus for drawing my attention to these examples (Institute of Anatomy Serial Nos. A-S 46-54, Accession Nos. 1183-91, received from. R.H. Goddard 1948; and Serial No. A-S 9, collected by A.P. Elkin 192728, No. E.60).

- A somewhat similar engraving (except that one wing is clearly on top of the fuselage and the second is underneath) is depicted in Plate 152 of Berndt, Berndt and Stanton (1982:143). 
line ahead of where the tail should be, suggesting that this engraving may depict a crashed aircraft.

It would seem that the details of these engravings provide historical evidence of Aboriginal observations of early aircraft. R.G. Kimber ${ }^{8}$ reports that the engraved pearlshell pendant used for this cover illustration was purchased from an Alice Springs shop-keeper to whom Aborigines offered many artefacts for sale in the early 1970s. Enquiries indicated that the seller had almost certainly been an elderly Warlpiri man of Yuendumu settlement. Further enquiries of Warlpiri and Anmatjera Aborigines indicated that the individual owner had the right to make such a sale, and that this owner had probably been a senior Tjangala man who had worked at both The Granites and Tanami gold-fields. Kimber notes that the engraved designs on the reverse side of the pearlshell include depictions of a motor-vehicle. On the basis of their form, the nature of their execution and the impact that aeroplanes and motor-vehicles had in the 1930s, he concludes that these engravings date from the 1930s (possibly late 1920s) and suggests that experiences at The Granites may have influenced the artist's depiction. His recent conversations with Aborigines suggest two other possibilities in identifying the 'crashed' aircraft in this pearlshell design. One is 'Kookaburra' (discussed above). The other is an aircraft first mentioned to Kimber about 1976, and cited again when Warlpiri and Anmatjera discussed publication of the cover illustration. Kimber's understanding is that parts - or most of this aeroplane still exist in the Tanami area and that it was almost certainly involved in a crash.

In the 1930s aeroplanes fell out of the skies almost as often as they stayed up. Kimber accepts my proposal of the Gypsy Moth D.H. 60 as a 'likely' identification of the aircraft depicted in a portion of this engraving. After half a century both memories and written records of the majority of crashes and aerial searches in central Australia are blurred. All we know with certainty is that the artist who laboriously incised this pearlshell used keen observation and the artistic conventions of his own society to make an enduring record of a phenomenon which was new and important in the history of this region.

AUSTRALIAN NATIONAL UNIVERSITY

8 I am most grateful to R.G. Kimber for his helpful comments (personal communication). 


\section{BIBLIOGRAPHY}

Berndt, Ronald M. and Catherine H. Berndt with John E. Stanton. Aboriginal Australian art: a visual perspective. Sydney, 1982.

Blakeley, Frederick. Dream millions: new light on Lasseter's lost reef. Sydney, 1972.

Clune, Frank. Last of the Australian explorers: the story of Donald Mackay. Sydney, 1942.

Coote, Errol. Hell's airport: the key to Lasseter's gold reef. Sydney, 1934.

Davis, Pedr. Kookaburta: the most compelling story in Australia's aviation history. Sydney, 1980.

Kimber, R.G. 'Walawumu, the giant eaglehawk: Aboriginal reminiscences of aircraft in central Australia, 1921-1931', Aboriginal History, 6(1), 1982:49-60.

Nash, David. 'Aboriginal knowledge of the aeroplane "Kookaburra", Aboriginal History, 6(1), 1982:61-73.

Pentland, Geoffrey G. Aircraft of the R.A.A.F. 1921-78. Melbourne, 1978. 